30. Kabsch. -Thèse de Würzburg, 1891.

31. Knapp.-Arch.f. Ophthal., XIV, p. 255, 1868.

32. Lang.-Trans. Ophthal. Soc. U.K., XXIX, p. 156, 1909.

33. Lawford and Edmunds - Trans. Ophthal. Soc., U.K., VII, p. 208, 1886.

34. Idem.-St. Thomas's Hosp. Rep., XI, p. 171. 1886.

35. Leber.-Graefe-Saemisch Handbuch, V, p. 907, 1877.

36. Leber u. Deutschmann.-Arch.f. Ophthal., XXVII, i, p. 2 72, 1881.

37. Mackenzie. - Text-book, 4th edit., p. 1052.

38. Magnus -Die Sehnervenblïtung, Leipzig, 1874.

39. Manx. -Deut. Arch. f. Klin. Med., IX, p. 339, 1872.

40. Mardellis. - Thèse de Lyons, 1900.

11. Michel.-Arch. J. Ophthal., XXIII, pp. 2, 216, 1877.

42. Nettleship.-Ophthal. Rev., XIV, p. 97, 1895.

43. Nicod.-Thèse de Lyons, 1906.

44. Oishi.-Arch.f Augenheilk., LXI, p, 17, 1908.

45. Panas. - "Traité des Maladies des Yeux."' I, p. 698. 1894.

46. Idem.-Arch. d'Ophtal., XXII, p. 624, 1895.

47. Parinaud.-Annal. d'Ocul., LXXXII, p. 26, 1879.

48. Idem. - Ibid, CXIV, p. 5, 1895.

49. Paton and Holmes. - Trans. Ophthal.Soc. U.K., XXXI, p. 117, 1911.

50. Priestley-Smith. - Trans. Ophthal. Soc. U.K., IV, p. 271, 1884.

51. Rollet.-Rev. Gén. d'Ophtal., XXVII. p. 49, 1908.

52. Schnaudigel.-Arch.f. Ophthal., XLVIII, pp. 3, 460, 1899.

53. Schwalbe.- "Lebrbuch der Anatomie des Auges," Erlangen, 1887.

54. Schmidt-Rimpler.-Arch. f. Augenheilk., XII, 1883.

55. de Schweinitz and Holloway.-Trans. Amer. Ophthal. Soc., XIII, p. 120, 1912.

56. Sicard -Quoted by Dupuy-Dutemps

57. Silcock.-Trans. Ophthal. Soc. U.K., IV., p. 274, 1884.

58. Symonds.-Quart. Jl. Med., XVIII, p. 93, 1924.

59. Talko.-Klin. Monatsbl. f. Augenheilk., XI, p. 341. 1873.

60. Thenevet. -Thèse de Lyons, 1894.

61. Terson.-Annal. d'Ocul., CXI.VII, p. 410, 1912.

62. Tiegel.-Thèse de Breslau, 1904.

63. Turnbull.-Brain, XII, p. 50, 1918.

64. Uhthoff.-Berichte Ophthal. Gesellsch., Heidelberg, p. 143, 1901.

65 Wilbrand u. Saenger.-Neurol. des Auges. III, p. 766.

66. Williams.-Brit. Med. Jl., I, p. 157, 1882.

67. Zacher.-Neurol. Centraibl., II, p. 125, 1883.

\title{
CENTRIPETAL FAN SCOTOMA IN GLAUCOMA
}

\author{
$\because$ \\ David Priestley Smith, M.B. \\ BIRMINGHAM
}

THE accompanying maps of the field of vision, with the exception of Fig. 25, belong to cases of chronic glaucoma. They are selected as having one noticeable feature in common, namely, a scotoma tapering from the periphery of the field towards the fixation point, and not connected with-nor leading towardsMariotte's Blind Spot. Fig. 3 is a striking specimen of the type. Fig. 22 is an exception in that it includes the region of the Blind Spot. Some of them were shown at a meeting of the Midland 
Ophthalmological Society in February, 1923. As the method by which they were obtained is of crucial importance, I give it in full. They were made by myself, on private patients, and in nearly all cases the findings were checked by re-mapping on, at least, one, and in most cases two or more subsequent occasions.

In testing the field in chronic glaucoma, or suspected chronic glaucoma, I begin with-and spend most time on-the central parts, for central vision is the most important. In a fair number of cases I do not feel it necessary to carry the examination further towards the periphery than the 40 or 50 -degree circles, which is an advantage if the patient is fatigued or one is short of time. [See Figs. 19, 20, 21, 23 and 24.] And I use the circular method more than the radial, because in chronic glaucoma the borders of the area of maximum blindness are generally more radial than concentric within 40 or 50 degrees of the fixation point; and, of course, the border is more accurately located when the test-object meets it at something like a right angle than when it meets it at a grazing incidence. In fact the "spike" menacing central vision, in cases like Figs. 1, 2, and 4, might easily be missed altogether, in that stage of the disease, by radial testing, and there is hardly one of the present series which could be properly defined by that method.

My usual procedure is as follows:- The test is made by daylight, using the Priestley Smith perimeter with cloth-faced arc, and, in most cases, the diameter of the test-object is $1 / 100$ of the distance from the eye $(2.5 \mathrm{~mm}$. at $25 \mathrm{~cm}$.).

The test-object is placed first at ten degrees from the fixation point, and moved round on this circle; if no defect is found, the $20,30,40$, and 50-degree circles are tested in the same way, and if no defect is found on any of them I test the field no further on that occasion. But if I do find a defect on, say the 10-degree circle, I test the 5-degree circle, and if this also shows a defect, I test the $2 \frac{1}{2}$-degree circle, if the patient fixes steadily enough. And similarly, on whatever circle a defect is first found, one proceeds to examine on successively smaller circles, until the inner limit of the scotoma is located ; one then continues examining on successively larger circles from the one on which the defect was first encountered, increasing the radius by ten degrees, or sometimes only five degrees, at a time.

As pointed out above, the advantage of the circular method applies chiefly to the central parts of the field; outside the $\mathbf{4 0}$ or 50-degree circles the scotoma often spreads out like the mouth of a trumpet, and if one finds the border here, or anywhere else, more concentric than radial, it is, of course, better to move the test-object radially in that region. 
The black areas on the charts represent those parts of the field in which the test-object is not perceived at all; the dotted areas represent the parts in which it is noticeably faint. This "faint" area generally has a definable edge. In a case which is getting worse one finds that the area of relative scotoma, if present, gradually becomes absolute, and that there is a fresh zone of relative blindness which, in its turn, becomes total. That is to say : the scotoma spreads like a lady's fan being opened out and pushed towards the fixation point. It may be said to "seek" the fixation point; hence the term "centripetal." Figs. 23 and 24 show the opening out of the fan well in one and the same eye. They also illustrate another phenomenon of some importance, namely, that sometimes the apex of the scotoma, when it has nearly reached the fixation point, ceases to advance appreciably for a considerable time-in the above case, for several yearsthough the fan continues to "open" as hitherto. This particular patient was old, and was developing cataract, so one did not urge operation against his decided wish to the contrary after having the pros and cons explained to him*

I think that these maps may be taken as fairly correct, for it would require very considerable inaccuracy to produce most of them if the scotoma did not taper towards the fixation point. And the number, though not large, is, I think, sufficient to show that this type of scotoma is far from rare in chronic glaucoma.

The maps shown here were made in the ordinary course of practice during 1922,1923 , and 1924, and there were nine more of the same type which I have not reproduced, that is to say 32 altogether. The total number of chronic glaucoma maps made during this period was 44 . The number of patients to whom these eyes belonged was 38 , the reason for their providing only 44 maps between them being that in eleven eyes the scotoma could not be mapped because the fixation point was lost; in four others the scotoma was not sharply enough defined to map, and in others

* On the Priestley Smith perimeter the chart faces the examiner and revolves as the arc is moved round. For circular testing a pencil is held, on a rest, opposite the circle being tested, and, as the chart revolves, is pressed against it whenever the patient loses sight of the test-object and kept pressed against it until the test-object comes into sight again. This makes a line from one edge of the scotoma to the other on that particular circle, and by joining the ends of these lines on adjacent circles one obtains the outline of the scotoma.

Where the test-object is perceived only faintly one presses the pencil against the chart intermittently instead of continuously, making a dotted line. fit the border of the scotoma one moves the test-object in and out of the blind area once or twice to locate it accurately. And one varies the rate of movement as one finds best.

For radial testing with this instrument one uses a test-object on a wand, locking the arc of the perimeter at the meridian being tested, and marking the chart with a short pencil line in the position of the edge of the scotoma. 
I could not detect any loss of field in the one eye though the fellow eye was definitely glaucomatous.*

As stated above, centripetal fan scotomata constituted 32 out of 44 mappable scotomata, i.e., 73 per cent., in the period under review.

Broad sector-shaped defects of the field, with the apex directed towards the fixation point, have been described by others as sometimes occurring in chronic glaucoma; but they are not often mentioned, and the narrow, spike-like scotomata do not appear to have been described at all; which would be accounted for by

R.

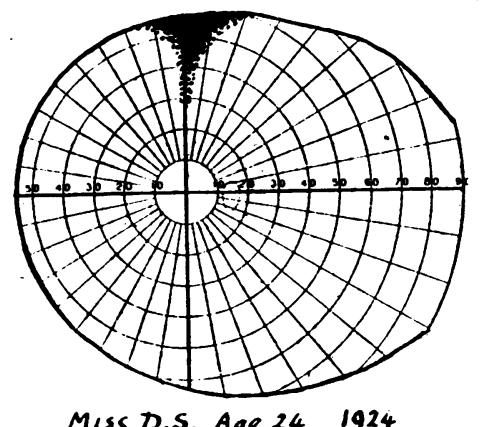

FIG. 25.

comparatively infrequent use, at any rate until recently, of methods other than the radial.

It is not only in chronic glaucoma that scotomata with radial edges occur. In hemianopia, whether complete or quadrantic, we have a universally recognized example of such a form. And Fig. 25 shows a typical "spike" in a case of subsiding optic neuritis with commencing optic atrophy in a patient of twentyfour who, as operation proved, had a cerebellar tumour. (The fellow field showed no defect.)

I take it that no one would rely upon the radial method for mapping a hemianopia, but this article is written in the belief that it will still bear emphasizing that that method by itself gives us quite inadequate information as to defect in other diseases also, the commonest being chronic glaucoma.

*Under the term "chronic glaucoma" I include only eyes which present cupping of the disc, and raised intraocular pressure, and loss of field. Cases in which any one of these three is missing are excluded. 
L.

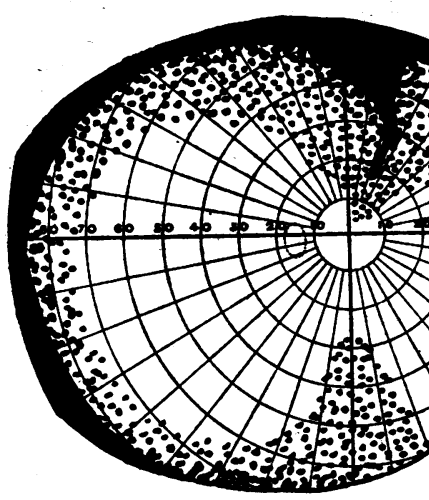

FIG 1.

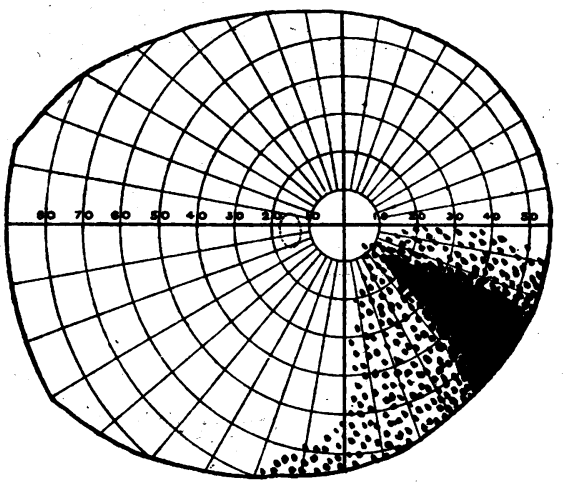

Mt H.G., Age 75. 1923 FIG. 3.

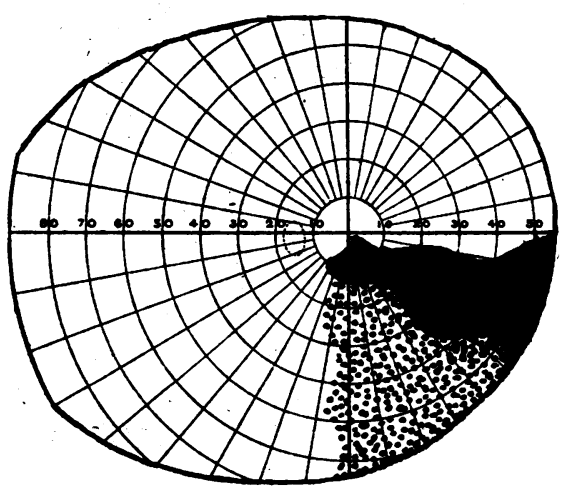

Miss S.E.N., Age 56. 1922 FIG. 5.
Mrse.T. Age 53.

1922

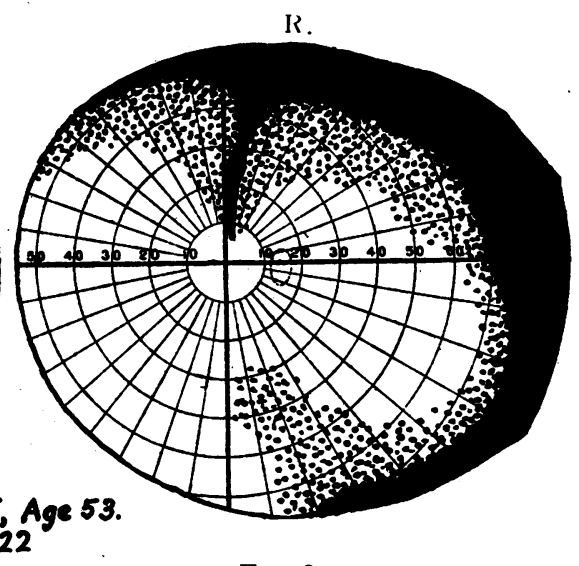

FIG 2.

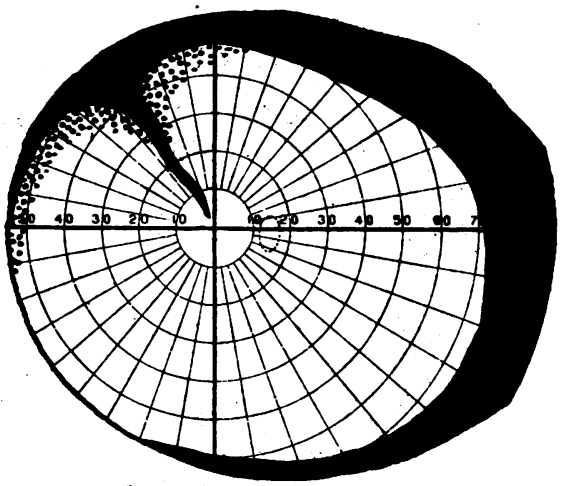

Mrs D.K., Age 66: 1922

FIG. 4.

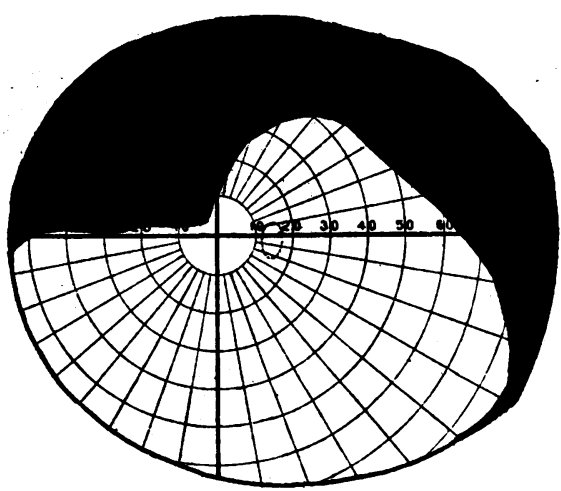

MtsA.J.J., Age 68. 1924

IIG. 6. 


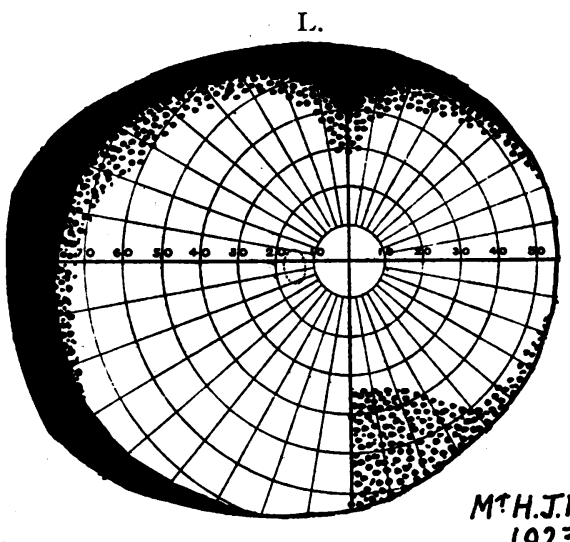

FIG. 7.

1923
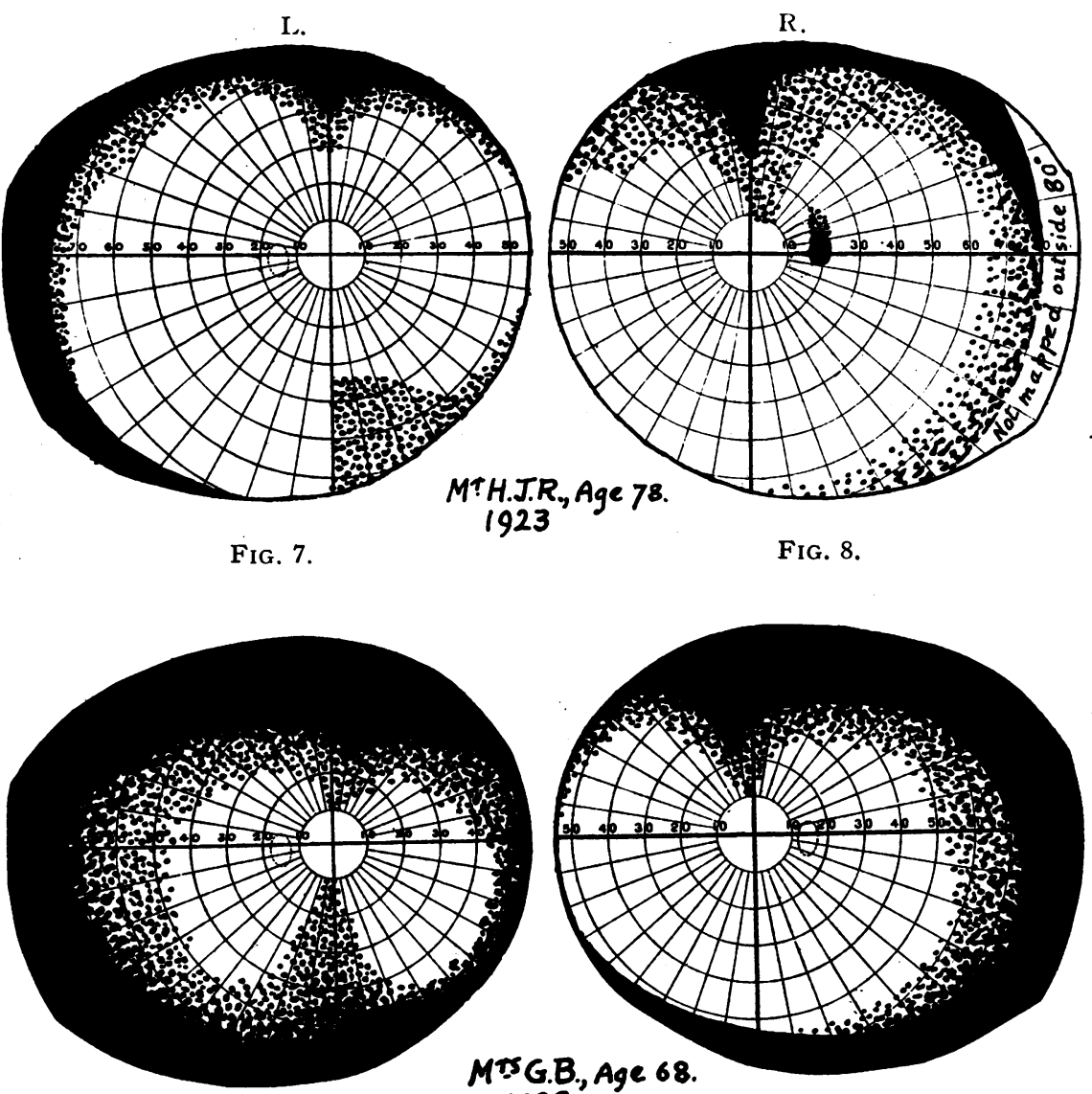

MTsG.B., Age 68.

FIG. 9. 1923

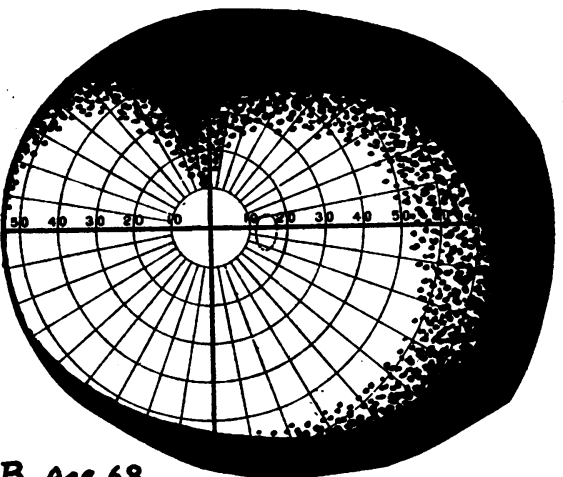

FIG. 8 .

FIG. 10.
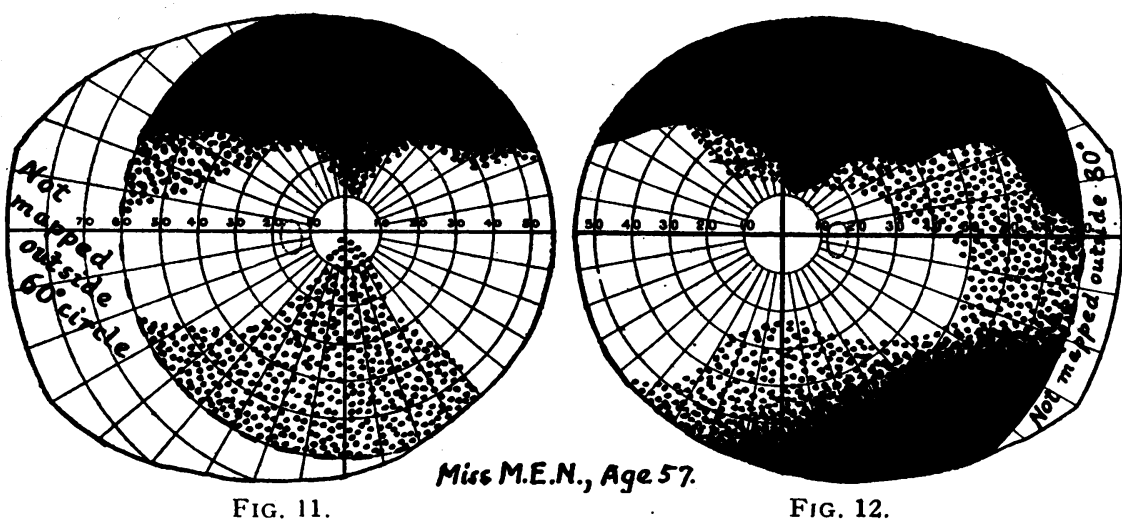

FIG. 12. 
Centripetal Fan Scotoma in Glaucoma

L.
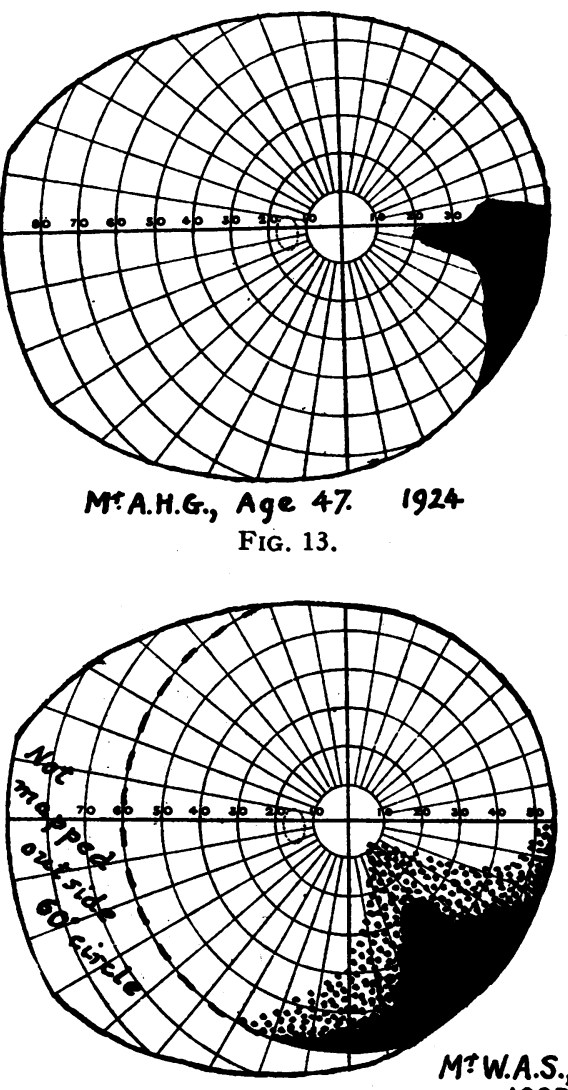

FIG. 15.

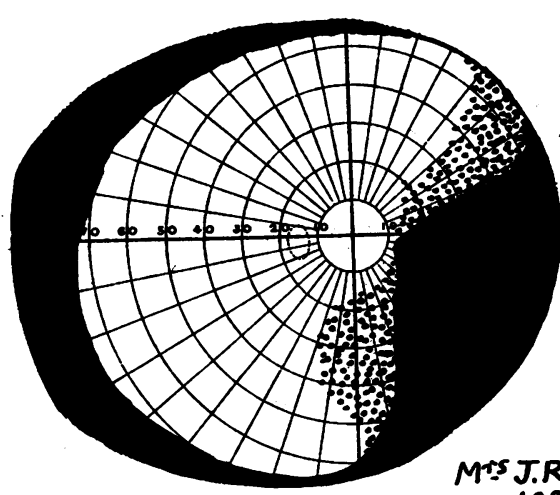

FIG. 17.

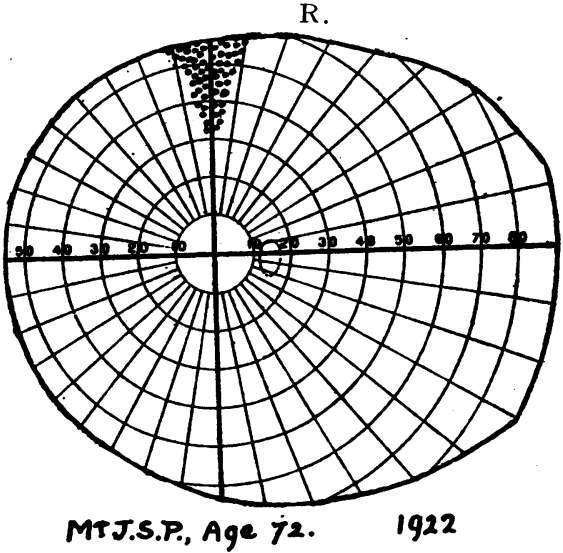

FIG. 14 .

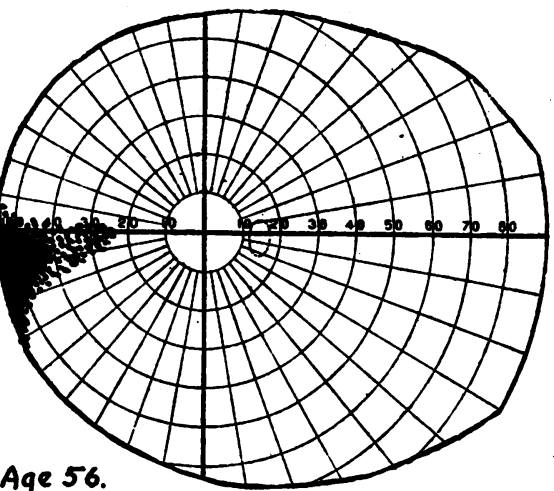

Fig. 16.

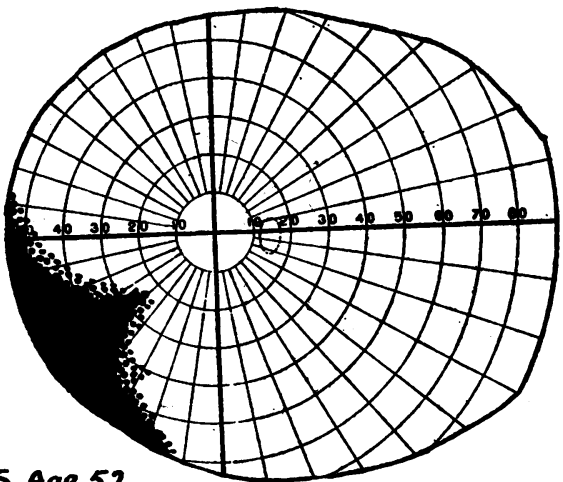
1924

FIG. 18. 798

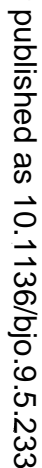

음

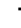

হ

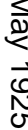

뭉$$
\text { 政 }
$$

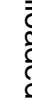

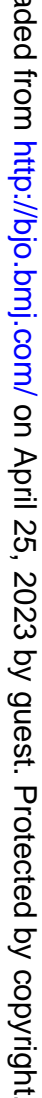



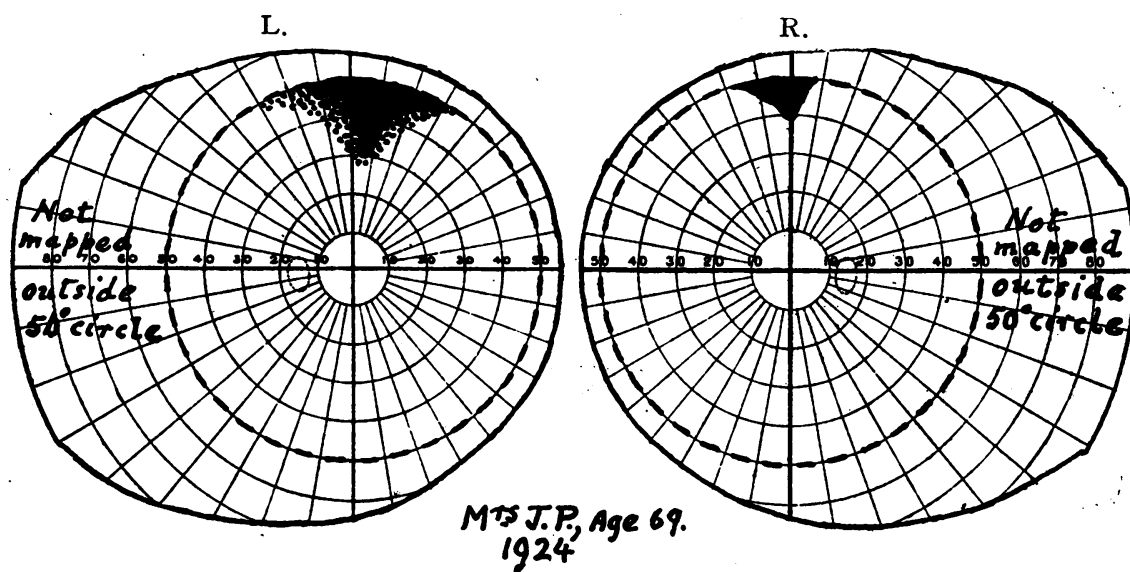

1924

FIG 19.

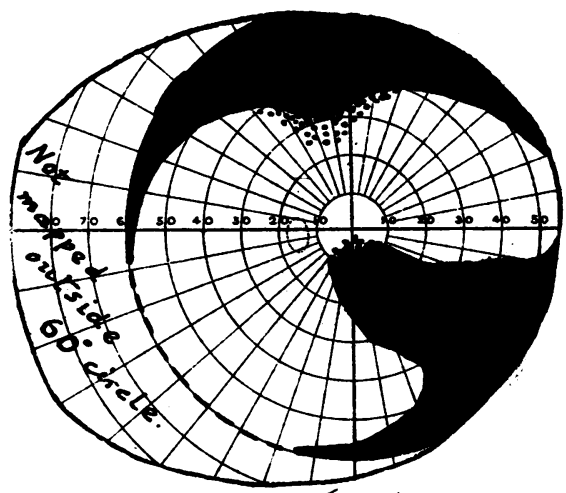

MะW.K., Age 78.

1924

FIG. 21

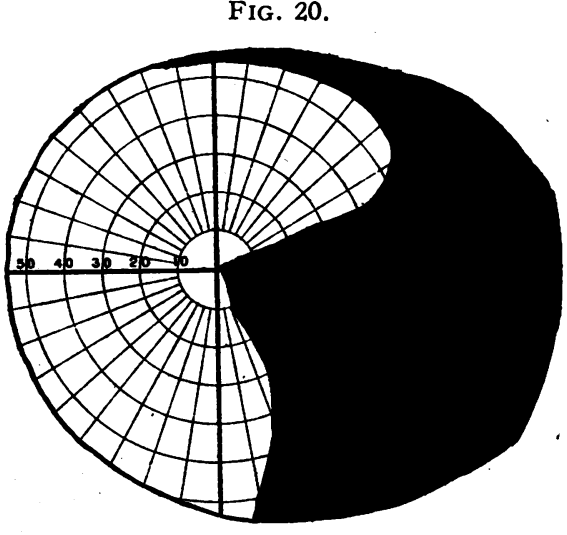

$M \pm$ J.G., Age 71. 1924

FIG. 22.

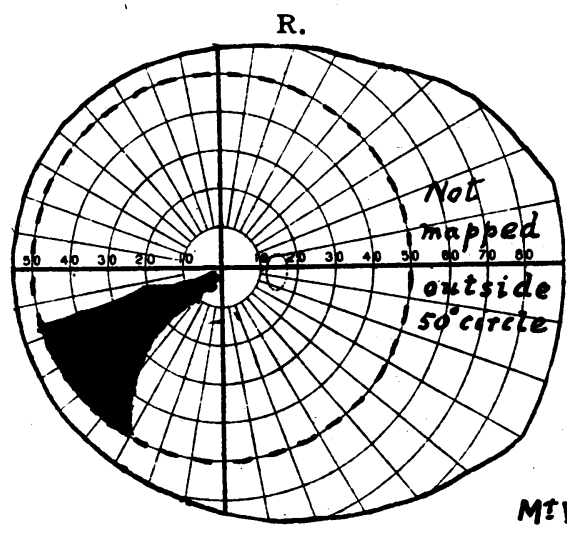

MtW.J.

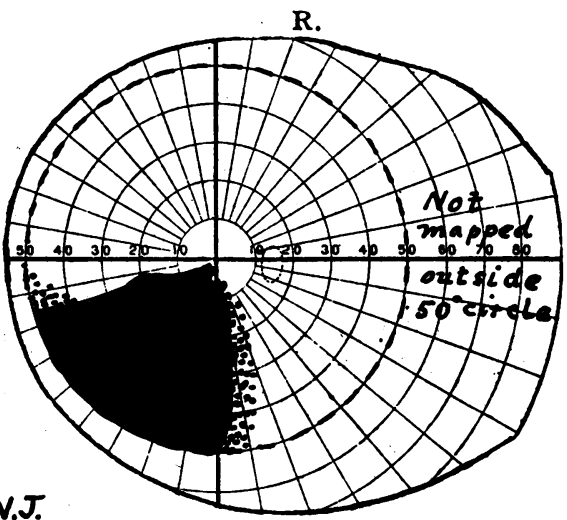

1919. Age 82.

Fig. 23.

1923. Age 86.

Fig. 24. 